\title{
LAS PRÁCTICAS POLÍTICAS DEL PARTIDO COMUNISTA DE LA ARGENTINA ANTE LA GUERRA CIVIL ESPAÑOLA Y SU RELACIÓN CON LA INTERNACIONAL COMUNISTA ${ }^{1}$
}

\section{THE POLITICAL PRACTICES OF THE COMMUNIST PARTY OF ARGENTINA IN RESPONSE OF THE SPANISH CIVIL WAR AND ITS RELATION WITH THE INTERNATIONAL COMMUNIST}

\author{
Víctor Augusto Piemonte \\ Universidad de Buenos Aires/ \\ Consejo Nacional de Investigaciones Científicas y Técnicas
}

Entregado el 24-10-2014 y aceptado el 3-11-2015.

\begin{abstract}
Resumen: Emergido en la cultura política argentina en el mismo momento en que tuvo lugar el ascenso de Mussolini al poder en Italia, el antifascismo argentino experimentó un fuerte desarrollo con el estallido de la guerra civil española. Si bien la participación del Partido Comunista de la Argentina (PCA) en favor de la Segunda República española adquirió gran notoriedad en la sociedad argentina, no ha sido objeto de estudio entre los diversos temas abordados por la historiografía referida a la Guerra Civil de España. Este artículo busca ser un primer intento dirigido a recuperar y analizar las tareas de apoyo a la causa republicana contenidas en el marco de la campaña antifascista llevada adelante por el PCA. La hipótesis es que el compromiso del PCA con la coyuntura internacional fue especialmente intenso a partir del modo de relacionarse con la Internacional Comunista que había construido la propia sección argentina tras un
\end{abstract} artículo.

${ }^{1}$ Agradezco los comentarios formulados por los evaluadores anónimos del presente 
proceso de pérdida de su autonomía relativa culminado a fines de la década de 1920.

Palabras clave: Partido Comunista de la Argentina - Internacional Comunista - Guerra Civil Española - Frente Popular - Antifascismo

\begin{abstract}
Emerging within the Argentinean political culture at the same time of Mussolini's ascent to the power in Italy, the Argentinean antifascism experienced a strong development with the outbreak of the Spanish Civil War. Even thought the participation of the Communist Party of Argentina (PCA) in favor of the Spanish Second Republic gained great fame in the Argentinean society, this subject has not been studied among the various topics discussed by the historiography referred to the Spanish Civil War. This article seeks to be a first attempt aimed to retrieve and analyze the tasks that supported the Republican cause contained within the antifascist campaign by the PCA. The hypothesis is that the compromise of the PCA with the international juncture was especially intense in terms of the mode of relating with the Communist International which was constructed by the own Argentinean section after a process of losing their relative autonomy ending in the late 1920s.
\end{abstract}

Key words: Communist Party of Argentina - Communist International Spanish Civil War - Popular Front -Antifascism 


\section{Introducción}

El levantamiento militar encabezado por el coronel Casado el 5 de marzo de 1939 no sólo fue el comienzo de la última etapa de la Guerra Civil que se había iniciado en España en julio de 1936, sino que, a su vez, representó el paroxismo al que habían arribado unas relaciones de fuerza siempre discordantes hacia el interior del bando republicano. Si la refriega interna tuvo lugar fue porque, desde los mismos comienzos de la Segunda República, convivían en el campo político español numerosas tendencias encarnadas en organizaciones políticas y sindicales de distinto signo. Cada una de ellas poseía una forma propia de entender los procedimientos operativos que eran requeridos para llevar adelante la transformación social y económica que, con matices también variables, se habían propuesto realizar a partir de la emergencia del gobierno republicano. Asimismo, pese a que su estallido se produjo dentro de confines geográficos precisos, la Guerra Civil Española fue, en más de un sentido, una guerra de carácter internacional. Más allá de las distintas reacciones que fue adoptando a lo largo de la coyuntura, la Unión Soviética acusó un marcado interés por los acontecimientos suscitados en España y entabló una compleja relación con el Partido Comunista de España (PCE). Esta situación repercutió en forma directa en los partidos comunistas nacionales que formaban parte del «partido comunista de la revolución mundial».

El estallido de la Guerra Civil de España fue un momento crucial en la consolidación y expansión de la lucha antifascista en Argentina. El antifascismo se había erigido desde el ascenso del fascismo en Italia en una parte central de la cultura política de la Argentina y su existencia se prolongó hasta entrada la década de 1960 , pero sin dudas fue con la guerra de 1936 cuando la lucha antifascista dejó de convertirse en «una causa más amiga que realmente propia» ${ }^{2}$. Al momento de irrumpir en la escena política vernácula, el Partido Comunista de la Argentina (PCA) cimentó su gravitación social entre las masas trabajadoras del país a partir de una legitimación conseguida en el hecho de haberse erigido en el primer partido comunista de América Latina. La dirección del PCA dio lugar por sí mismo a un proceso de pérdida de su autonomía relativa respecto de la Internacional Comunista (IC) que se cristalizó a fines de la década de

2 Andrés Bisso, El antifascismo argentino. Selección documental y estudio preliminar, Buenos Aires, CeDInCI Editores/Buenos Libros, 2007, p. 63. 
1920 en el triunfo definitivo de la posición internacionalista que anteponía las necesidades de la Unión Soviética a las propuestas que bregaban por el desarrollo de un comunismo de raigambre nacional. ${ }^{3}$ Esta realidad condicionó la respuesta del PCA al alzamiento militar en España, tornándola especialmente intensa en su compromiso desde el comienzo de las hostilidades. No estamos afirmando aquí que la experiencia antifascista se haya limitado al campo de acción del comunismo - lo cual sería por otro lado, insostenible - , sino que nos limitamos a las prácticas contenidas en la campaña antifascista conducida por nuestro objeto de estudio: el PCA. De hecho, la conformación de la Asociación de Intelectuales, Artistas, Periodistas y Escritores, surgida en Buenos Aires en 1935 y activa hasta 1943, organización de lucha antifascista que adquirió gran notoriedad por su acción a favor de la defensa de la Segunda República española, estuvo integrada por intelectuales procedentes de diversas corrientes de pensamiento, vinculados casi de manera unánime a las diferentes fuerzas de izquierda vigentes en la Argentina. ${ }^{4}$ En este sentido, el objetivo de este estudio es recuperar y analizar algunas de las intervenciones más salientes del PCA en relación a la campaña para la defensa del gobierno constitucional español.

${ }^{3}$ Hemos analizado esta transformación en los siguientes artículos: Víctor Augusto Piemonte, «La compleja relación entre la dirección del Partido Comunista de la Argentina y la representación de la Comintern ante la ruptura de 1928», Políticas de la Memoria. Anuario de Investigación del CeDInCI, N. ${ }^{\circ}$ 16, verano 2015/16; «Lucha de facciones al interior del Partido Comunista de la Argentina hacia fines de los años veinte: la ‘cuestión Penelón' y el rol de la Tercera Internacional», Cuadernos de Historia, N. ${ }^{\circ} 43$, diciembre 2015; «Un estudio preliminar acerca de la relación entre el Partido Comunista de la Argentina y el Partido Comunista de la Unión Soviética en tiempos de la Tercera Internacional: algunas reflexiones exploratorias en torno a la importancia de su análisis», Nuevo Mundo. Mundos Nuevos, N. ${ }^{\circ}$ 15; «El Partido Comunista de la Argentina ante la Segunda Guerra Mundial y la disolución de la Internacional Comunista, 1939-1943», Pacarina del Sur. Revista de Pensamiento Crítico Latinoamericano, año 5, N. ${ }^{\circ} 18$, enero-marzo 2014; «La Internacional Comunista y su Sección Argentina: discordia en torno del «frente único» a comienzos de la década de 1920», Revista Izquierdas, N. ${ }^{\circ} 19$, 2014; «Comunistas oficiales y extraoficiales en competencia: el rol asignado a la Internacional ante el surgimiento de la facción "chispista"» del PC de la Argentina», Archivos de Historia del Movimiento Obrero y la Izquierda, año III, N. ${ }^{\circ}$ 5, 2014.

${ }^{4}$ Cf. Adrián Celentano, «Ideas e intelectuales en la formación de una red sudamericana antifascista», Literatura y Lingüística, N. ${ }^{\circ}$ 17, pp. 195-218; Ricardo Pasolini, «Scribere in eos qui possunt proscribere: Consideraciones sobre intelectuales y prensa antifascista en Buenos Aires y París durante el período de entreguerra», Prismas, 2008, vol. 12, N. ${ }^{\circ}$, junio de 2008 , s/p. 


\section{Consideraciones sobre la historiografía a propósito de la participación en la Guerra Civil española}

Resulta llamativo que no se haya investigado todavía la relación del PCA con la Segunda República española en tiempos de la Guerra Civil. En este sentido, las tareas organizativas a nivel partidario desempeñadas por la máxima figura del comunismo argentino, Victorio Codovilla, no han sido destinatarias del análisis que ameritan, es decir, de una interpretación que rompa el aislamiento de la acción individual y la ponga en relación con el complejo problemático que la excede y le da sentido. Por el contrario, se reconoce la importancia de su participación y -aunque en forma epidérmica - se la delimita, pero no se la disecciona y mucho menos se la comprueba. De hecho, se ha negado cualquier importancia al hecho de que la Comisión Política encargada de gestionar con el Consejo Militar la organización de las Brigadas Internacionales, que estuvo integrada por el secretario general del PCE y constituye uno de los aspectos más atendidos por la historiografía internacional, contó también con la participación atenta de Codovilla. ${ }^{5} \mathrm{Y}$ es que actualmente subsiste en la historiografía una situación de rezago explicativo en torno de la enorme cantidad de temáticas englobadas por la guerra iniciada 1936 y sus múltiples conexiones con el desarrollo de la política argentina.

Si bien el vacío historiográfico que envuelve la participación argentina en la Guerra Civil de España ha comenzado a ser revertido a partir de la generación relativamente constante de estudios sistemáticos desde 1986, la cual ha logrado mayor continuidad en el último decenio, también es evidente que la producción intelectual destinada a dar cuenta en clave interpretativa de los distintos nudos problemáticos que la asonada franquista generó o coadyuvó a generar en la Argentina - en encadenamientos hacia delante y hacia atrás - continúa siendo relativamente escueta. Los primeros escritos referidos a estas cuestiones estuvieron, lógicamente, orientados a dar cuenta de un cúmulo de generalidades que empezaron a llenar el vacío de conocimiento vigente. ${ }^{6}$ Una vez que estuvieron sentados los pre-

5 Valerian Goncharov, El camarada Victorio. Semblanza de V. Codovilla, Fundamentos, Buenos Aires, 1981, p. 72.

${ }^{6}$ Ernesto Goldar, Los argentinos y la Guerra Civil Española, Contrapunto, Buenos Aires, 1986. [Aquí utilizamos la edición de Plus Ultra de 1996]. Hubo un precedente para el estudio de Goldar, y es el artículo de Enrique Pereira, que irrumpió en la historiografía en solitario, puesto que no pudo dialogar con ningún interlocutor. El trabajo de Pereira distribuye por 
cedentes básicos comenzó a tener lugar una producción más específica, ocupada en recortes temáticos específicos y desarrollados con una mayor rigurosidad científica. Las áreas de interés estuvieron concentradas en las repercusiones registradas en las culturas políticas nacional y regionales, ${ }^{7}$

igual responsabilidades ante el estallido bélico y sus consecuencias, dando cuenta de una República asediada tanto por derecha como por izquierda. Además de poner en un mismo nivel la acción de los golpistas y la reacción de los constitucionales, se vislumbra en Pereira la concepción de un pueblo de España inerte, sin iniciativa ni vigor, al que no le queda más opción que la de padecer «las acechanzas y trampas que les tendían la izquierda delirante y la derecha reaccionaria». Su mirada reduccionista lo lleva a pergeñar una defensa republicana a todas luces fraudulenta por parte de anarquistas, comunistas, trotskistas y separatistas. Por todos estos motivos, estimamos, el artículo comentado ha sido obviado por la historiografía subsiguiente. Enrique Pereira, «La guerra civil española en la Argentina», Todo es Historia, año X, N. 110, julio de 1976. La bisagra que inauguró el paso a los estudios sistemáticos basados en la utilización de fuentes documentales vino dado por el amplio arco temático abordado por Mónica Quijada en Aires de República, aires de Cruzada: la Guerra Civil Española en Argentina, Sendai, Barcelona, 1991. M. Quijada, Relaciones hispano-argentinas, 1936-1948. Coyuntura de Crisis, Tesis Doctoral, Universidad Complutense, Madrid, 1989; Mark Falcoff, «Argentina», en Mark Falkoff \& Fredrick Pike (Eds.), The Spanish Civil War, 1936-1939. American Hemispheric Perspectives, University of Nebraska Press, Lincoln and London, 1982; Lidia Bocanegra, «Argentina en la Guerra de España», en Juan Bautista Vilar y Abdón Mateos (Eds.), Historia del Presente, N. ${ }^{\circ} 12$, 2da. época, Madrid, Eneida, 2008; Enrique Mayochi, «La Guerra Civil Española», La Nación, N. 888, Buenos Aires, julio de 1986.

7 María Dolores Béjar, «Cómo vieron y vivieron los argentinos la contienda», Todo es Historia, N. ${ }^{\circ}$ 148, 1979; Ducezio Alejandro Licitra, La política del gobierno de Burgos en Argentina y Uruguay durante la Guerra Civil Española, Tesis de Licenciatura, Facultad de Geografía e Historia de la Universidad Complutense de Madrid, 1986; Marilú Bou, «1936: el fraude, el frente, el fascismo», Todo es Historia, año XIX, N. 237, febrero de 1987; Mónica Quijada, «Los españoles de la Argentina ante la guerra civil española: las instituciones de la comunidad», en Pedro Pérez Herrero, Inmigración, integración e imagen de los latinoamericanos en España. (1938-1987). Apuntes introductorias, Cuadernos sobre Cultura Iberoamericana, OEI, Madrid, 1988; Mónica Quijada, Nuria Tabanera y Manuel Azcona, «Actitudes ante la guerra civil española en las sociedades receptoras», en AAVV, Historia general de la emigración española a Iberoamérica, vol. 1, Historia 16, Madrid, 1992; Beatriz Figallo, «La Argentina y el régimen primorriverista», Res Gesta, 1992, N. 31, 1992; Silvina Montenegro, La guerra civil española y la política argentina, Facultad de Geografía e Historia, Universidad Complutense de Madrid, Tesis Doctoral, inédita, 2002; Saúl Luis Casas, La Guerra Civil Española y el Antifascismo en la Argentina 1936-1941. Las Baleares y la Ayuda a la República, Facultad de Humanidades y Ciencias de la Educación, Universidad Nacional de La Plata, Tesis de Maestría, inédita, 2005; Saúl Luis Casas, «El antifascismo y la lucha política en la Argentina en el contexto de la Guerra Civil Española», Congreso Internacional La Guerra Civil Española 1936-1939, Sociedad Estatal de Conmemoraciones Culturales, 2006 [Tomado de http://www.secc.es/media/docs/8_1_SL_ Casas.pdf. Ultimo acceso: 2/2/2012]; Luis Alberto Romero, «La Guerra Civil Española y la 
la recepción de los acontecimientos en la prensa,${ }^{8}$ los movimientos de solidaridad expresados en las campañas para colectar fondos y en el enrolamiento de voluntarios, ${ }^{9}$ las políticas estatales de asilo para la recepción

polarización ideológica y política: la Argentina 1936-1946», Anuario Colombiano de Historia Social y de la Cultura, vol. 38, N.2 2, julio-diciembre 2011; Miguel Ángel De Marco (h), «Universitarios rosarinos en la recepción de exiliados republicanos españoles El decanato de Cortés Plá. 1934-1943», Revista de Historia Épocas, N. 11, 2015.

${ }^{8}$ Beatriz Figallo, «La II República Española en guerra: los planteamientos del gobierno de Largo Caballero a través del periódico 'Claridad'», Res Gesta, N. 27-28, 1990; María Jesús Comellas, «El estallido de la Guerra Civil Española en la prensa argentina», Res Gesta, N. ${ }^{\circ} 31$, Rosario, 1992; Víctor Trifone y Gustavo Svarzman, La repercusión de la guerra civil española en la Argentina (1936-1939), CEAL, Buenos Aires, 1993; Lidia Bocanegra, El fin de la Guerra Civil española y el exilio republicano: visiones y prácticas de la sociedad argentina a través de la prensa. El caso de Mar del Plata, 1939, Tesis Doctoral, Universidad de Lleida, inédita, 2006; Lidia Bocanegra, «El impacto del exilio republicano español en la sociedad argentina. Una visión a través de la prensa marplatense, 1939», Congreso Internacional: A 70 años de la Guerra Civil española, Ariadna Tucma: Revista Latinoamericana, 2007; Lidia Bocanegra, «El final de la Guerra Civil española en la prensa marplatense», Estudios Interdisciplinarios de América Latina y el Caribe, vol. 18, N. ${ }^{\circ}$ 2, 2008; Laurent Bonardi, «La guerre civile espagnole dans la presse argentine», Revista de Historia Actual, N. ${ }^{\circ}$ 7, 2009.

${ }^{9}$ Gino Baumann, Los Voluntarios Latinoamericanos: En las Brigadas Internacionales, las milicias, la retaguardia y el ejército republicano, Guayacán, San José de Costa Rica, 1997; Gino Baumann, Los voluntarios latinoamericanos en la Guerra Civil Española, Universidad de Castilla-La Mancha, Cuenca, 2009; Lidia Bocanegra, «La ayuda argentina a la República española. Un análisis a través del ejemplo marplatense, 1939», Congreso Internacional La Guerra Civil Española 1936-1939, Sociedad Estatal de Conmemoraciones Culturales [Tomado de http://www.secc.es/media/docs/8_2_Lidia_Bocanegra.pdf. Ultimo acceso: 2/2/2012], 2006; Graciela Mochkofsky, «Guerra Civil española: los argentinos que fueron a pelear contra Franco», Clarín, 4/6/2006; Lucas González, Jerónimo Boragina, Gustavo Dorado, Ernesto Sommaro, Voluntarios de Argentina en la Guerra Civil Española, Ediciones CCC, Buenos Aires, 2008; Jerónimo Boragina y Ernesto Sommaro, «Brigadistas por la República. Mar del Plata y la Guerra Civil Española», Todo es Historia, N. ${ }^{\circ}$ 468, julio de 2006; documental Esos Mismos Hombres - Voluntarios argentinos en la Guerra Civil Española», realizado por el Grupo de Historia Desde Debajo de Mar del Plata; Jerónimo Boragina, «Voluntarios de Argentina en la Guerra Civil española», El Rapto de Europa, junio de 2008; «Brigadistas argentinos en la guerra civil española, olvidados de la Historia», entrevista a Jerónimo Boragina, Publico.es, 8/10/2008; Jerónimo Boragina, «Carlos Kern Alemann, uno de tantos», Buenos Aires, Goethe Institut, 2009 [Tomado de http://www.goethe.de/wis/bib/prj/hmb/the/ami/es4898543.htm. Ultimo acceso: 21/4/2013]; Jerónimo Boragina, «Voluntarios argentinos en la Brigada XV Abraham Lincoln», The Volunteer, 1/6/2010 [Tomado de http://www.albavolunteer.org/2010/06/ voluntarios-argentinos-en-la-brigada-xv-abraham-lincoln/. Ultimo acceso: 18/4/2013]. Respecto de la participación militar, existe también un trabajo sobre la intervención de la marina argentina en la guerra, Beatriz Figallo, «Participación de la armada argentina durante la guerra civil española», Revista de Historia Naval, N. ${ }^{\circ}$ 10, 1985. 
de los refugiados. ${ }^{10}$ También se cuenta con algunos testimonios de participantes argentinos destacados..$^{11}$

Si bien los temas abordados por la historiografía argentina son variados y contribuyen todos ellos a arrojar luz sobre las implicancias de la Guerra Civil española en el acontecer político argentino de las fuerzas contestatarias al statu quo, en ningún caso los estudios tomaron por centro

10 Joe Robert Juárez, «Argentine neutrality, mediation, and asylum during the Spanish civil war», The Americas, vol. XIX, N. 4, 1963; Beatriz Figallo, La Argentina en la Guerra Civil Española (Defensa y aplicación del Derecho de Asilo), Instituto de la Facultad de Derecho y Ciencias Sociales de Rosario, Universidad Católica Argentina, Tesis de Licenciatura, inédita, 1984; Mónica Quijada y Jean Grugel, «Chile, Spain and Latin America: The Right of Asylum at the Onset of the Second World War», Journal of Latin American Studies, vol. 12, part 2, May 1990; Raanan Rein, «Otro escenario de lucha: franquistas y antifranquistas en la Argentina, 1936-1949», Ciclos en la historia, la economía y la sociedad, año V, vol. V, N. ${ }^{\circ}$, 2. ${ }^{\circ}$ semestre, 1995; Leonardo Senkman, «La Argentina neutral de 1940 ante los refugiados españoles y judíos», Ciclos en la historia, la economía y la sociedad año V, vol. V, nro. 9, 2..$^{\circ}$ semestre, 1995; Beatriz Figallo, La Argentina ante la guerra civil española: el asilo diplomático y el asilo naval, Universidad Católica Argentina, Rosario, 1996; Raanan Rein, «Francoist Spain and Latin America, 1936-1953», en Stein Ugelvik Larsen (Ed.), Fascism outside Europe. The European impulse against domestic conditions in the diffusion of global fascism, Columbia University Press, New York, 2001; Antonio Manuel Moral Roncal, «El asilo diplomático: un condicionante de las relaciones internacionales de la República durante la Guerra Civil», Congreso Internacional La Guerra Civil Española 1936-1939 [Tomado de http://www.secc.es/media/docs/6_4_Moral_ Roncal.pdf]; Beatriz Figallo, Diplomáticos y marinos argentinos durante la crisis española: los asilos de la Guerra Civil, Librería-Editorial Histórica, Buenos Aires, 2007; María Paula Cicogna, «Breve historia de los refugiados en Argentina durante el siglo XX», Historia Actual Online, N. 18, Invierno, 2009; Lidia Bocanegra, «La República Argentina: el debate sobre la guerra civil y la inmigración», en Abdón Mateos (Ed.): Ay de los vencidos. El exilio y los países de acogida, Eneida, Madrid, 2009; Elena Romero Pérez, «Persecución franquista contra los disidentes ¿Obsesión de sus representantes en el Cono Sur (Argentina-Chile)?», Revista de Historia Épocas, N. ${ }^{\circ} 11,2015$.

${ }^{11}$ Córdova Iturburu, España bajo el comando del pueblo, Buenos Aires, Acento, 1938; Bernardo Edelman, España contra el fascismo, JAEL, Buenos Aires, 1939; Victorio Codovilla, «José Díaz. Ejemplo de dirigente obrero y popular», Una trayectoria consecuente en la lucha por la liberación nacional y social del pueblo argentino, tomo I, Anteo, Buenos Aires, 1964; Juan José Real, «Recuerdos de la derrota y de la huída», en AAVV, Los que fueron a España, Crisis, Buenos Aires, 1973; Mika Etchebéhère, Mi guerra de España. Testimonio de una miliciana al mando de una columna del POUM, Alikornio, Barcelona, 2003; Fanny Edelman, Banderas. Pasiones. Camaradas, Buenos Aires, Dirple, 1996; Samuel Joukovsky, Uno de tantos (un argentino en la guerra civil española), s/e, Buenos Aires, 1998; Norma A. Jiménez, Testimonios republicanos de la Guerra Civil española, La rosa blindada, Buenos Aires, 2001; Graciela Mochkofsky, Tío Boris. Un héroe olvidado de la Guerra Civil Española, Sudamericana, Buenos Aires, 2006. 
de análisis al PCA; antes bien, este último fue objeto de menciones marginales cuando su incorporación resultó inevitable en función de la problemática tratada. No sorprende entonces que se haya dicho muy poco respecto de la participación específica del comunismo argentino ante los sucesos de España, quedando limitado su estudio a la intensa campaña de ayuda material y de reclutamiento de voluntarios, principalmente a través de su predominio dentro de la Federación de Organismos de Ayuda a la República Española (FOARE) ${ }^{12}$, conformada en agosto de 1937 con el fin de reunir ayuda material y humana para el frente de batalla. Esta deficiencia bibliográfica no se condice con el estrecho compromiso que dedicó el PCA a la lucha antifascista en España.

Como parte de una hipótesis original que merece ser abordada in extenso en estudios subsiguientes, consideramos aquí que el análisis de la participación de varios de los más destacados cuadros del PCA y de la Federación Juvenil Comunista argentina, permitirá, además de ampliar el conocimiento actual sobre la participación argentina en la Guerra Civil, comprender con mayor claridad la complejidad de la relación que la dirección de la sección argentina mantuvo con la IC. Es por esto que, aunque la actuación en la Península Ibérica de Victorio Codovilla, quien fue junto con Rodolfo Ghioldi el máximo exponente en la historia del PCA, ha sido recreada y analizada en forma meticulosa principalmente por los historiadores españoles Antonio Elorza y Marta Bizcarrondo, ${ }^{13}$ y pese a que algunas de sus observaciones y documentaciones aportadas fueron incidentalmente recogidas en otras investigaciones posteriores, ${ }^{14}$ lo cierto es

${ }^{12}$ La declaración de formación de la FOARE fue dada a publicidad en España Republicana, 14/8/1937, p. 5.

13 Antonio Elorza y Marta Bizcarrondo, Queridos camaradas. La Internacional Comunista y España. 1919-1939, Barcelona, Planeta, 1999.

14 Por citar algunos ejemplos recientes que mediante el acceso de fondos de archivo poco frecuentados constituyeron aportes novedosos o presentaron una línea interpretativa diferente respecto de aquella provista por Elorza y Bizcarrondo a propósito de las tareas realizadas en España por Codovilla, cabe mencionar el estudio referido a su participación en el Partido Socialista Unificado de Cataluña, José Luis Martín Ramos, Rojos contra Franco. Historia del PSUC, 1939-1947, Barcelona, Edhasa, 2002, pp. 25-122; En su documentada y profusa investigación sobre las relaciones entre la República española y la Unión Soviética, Angel Viñas ha relativizado la gravitación de Codovilla, llegando a sostener que su inacción en la crisis de mayo de 1937 se debió en gran parte al hecho de que «no era un estratega fino para un partido crecido, con ínfulas hegemónicas, en el epicentro de un conflicto que interactuaba con las bases del modelo de seguridad exterior más convincente para la URSS». A. Viñas, El escudo de la República. El oro de España, la apuesta 
que la injerencia de Codovilla no fue sino objeto de atención a partir de su interlocución entre Moscú y el PCE. Así, la elección de Codovilla para convertirse en «auténtico delegado-tutor» del PCE (que implicaba ocupar de hecho el lugar del secretario general y servir de enlace con Moscú) se basó en gran parte en cuestiones idiomáticas. Codovilla había sido señalado para suplantar al alemán Stöcker y al polaco Purmann. ${ }^{15}$ No obstante, planteamos aquí que en el papel clave que prestó a la reorganización del PCE, Codovilla no se limitó a cumplir un rol de ejecutor, sino que se preocupó por implementar una concepción particular de Partido Comunista integrado a la Tercera Internacional, y esta era la concepción que la dirección de la sección argentina pretendió para su partido desde que decidió privarse de su autonomía parcial. El líder del PCA intentó llevar a cabo en España la importación de una forma de centralización verticalista, supeditada a Moscú y contraria a toda posibilidad de expresión disidente, que desde unos pocos años antes se había convertido en una práctica naturalizada en la vida política de la sección argentina.

En otras palabras, no se realizó todavía ningún estudio que leyera la actuación de Codovilla en clave del sistema crítico-práctico cultivado por el PCA del momento, y más lejos todavía se está de contar con un análisis acerca de la importancia que tuvo para el comunismo argentino el desplazamiento de una parte muy importante de sus líderes. Tratándose de un partido «orientado hacia afuera» ${ }^{16}$ desde 1928 y organizado en base a las jerarquías y acostumbrado a tomar sus decisiones en forma verticalista, esta es una cuestión central que permitirá ahondar sobre la dinámica del PCA con el PCE, pero también con la IC, en la segunda mitad de la década de 1930, momento en que las coyunturas políticas nacional e internacional ponían en jaque el tan ansiado lugar de partido-guía ejercido por la sección argentina hacia los partidos comunistas de la región sudamericana.

soviética y los hechos de mayo de 1937, Barcelona, Crítica, 2010, p. 571, nota 37; Por su parte, y si bien uno de los estudios más recientes sobre Andreu Nin y su partido no mencionan a Codovilla (Pelai Pagès y Pepe Gutiérrez-Alvarez [Dirs.], El POUM y el caso Nin. Una historia abierta, Barcelona, Laertes, 2014), Boris Volodarsky analizó la colaboración directa de Codovilla con el NKVD soviético en los planes para reprimir al Partido Obrero de Unificación Marxista en Cataluña, en El caso Orlov. Los servicios secretos en la Guerra Civil española, Barcelona, Crítica, 2013; Stalin's Agent. The Life and Death of Alexander Orlov, Oxford, Oxford University Press, 2015, pp. 167, 188.

15 A. Elorza y M. Bizcarrondo, op. cit., pp. 116-117.

${ }^{16}$ Cf. Darío Cantón, Elecciones y partidos políticos en la Argentina. Historia, interpretación y balance: 1910-1966, Buenos Aires, Siglo XXI, 1973, p. 112. 


\section{Acontecimientos previos al levantamiento franquista}

En la década de 1930 la comunidad española en Argentina era demasiado grande como para que la repercusión de la Guerra Civil no fuera igualmente amplia entre sus miembros, superando la cifra de 300.000 españoles dentro de un total de habitantes en Buenos Aires que ascendía los 2,5 millones ${ }^{17}$. Cuando el conflicto español estalló, los distintos sectores de la sociedad argentina poseían ya una clara postura adoptada en lo referente a la situación ibérica, y es por eso que se volcaron con tanta velocidad y definición a apoyar a uno u otro bando. La historiadora Silvina Montenegro destacó que esta identificación palmaria se debió al hecho de que las fricciones españolas más inmediatamente imbricadas en la guerra peninsular en realidad se hallaban en danza desde unos pocos meses anteriores a su estallido, motivo por el cual, cuando la conflagración se transformó finalmente de potencia en acto, ésta resultó ser el producto de una realidad con la que todos se hallaban familiarizados. ${ }^{18} \mathrm{La}$ conmemoración del $1 .^{\circ}$ de mayo de 1936, con sus arengas contra el fascismo a partir del triunfo del Frente Popular español, aparecía así como el precedente directo en relación a la movilización popular ante la asonada franquista del 18 de julio. ${ }^{19}$.

En un acto público realizado en el centro cultural «Anatole France» de Buenos Aires el 15 de abril de 1932, el balance de Rodolfo Ghioldi sobre el primer año de vida del gobierno republicano español, en línea con la radicalización decretada por la IC en su VI Congreso, arrojaba que éste se había encontrado lejos de asumir una política revolucionaria: no había entregado la tierra al campesinado ni había dado lugar a la revolución agraria, las condiciones de vida de los trabajadores permanecían inmutables, las hostilidades contra los obreros expresadas en deportaciones y encarcelamientos habían continuado el curso impreso por el primorriverismo. ${ }^{20}$ Esta percepción se mantuvo en la postura oficial del PCA hasta que

17 Luis Alberto Romero, op. cit., p. 19.

18 Silvina Montenegro, op. cit., p. 61.

19 En opinión de Marianetti, el Día del Trabajador de 1936 representaba el inicio de la fase más avanzada en la defensa de las libertades democráticas y contra el fascismo. Benito Marianetti, Frente Popular. ¿Para qué? ¿Con quiénes? ¿Contra quién?, Ayax, Buenos Aires, 1936, p. 3.

20 «Realizose el acto polémico sobre la España republicana», Bandera Rojo. Diario obrero de la mañana [PCA], N. ${ }^{\circ} 17,17 / 4 / 1932$, p. 4. 
cambió por completo cuatro años más tarde. En primer lugar, el PCA interpretó que para salir de su encierro necesitaba promover el carácter universal - no clasista - de la guerra española. ${ }^{21}$ El número inaugural de Hoy, órgano oficial del PCA, establecía que

«La lucha que se desarrolla en España no interesa solamente a la clase obrera, interesa al pueblo en su conjunto. No son únicamente los obreros y campesinos españoles quienes empuñan las armas contra los facciosos, son también los nacionalistas vascos y catalanes, las minorías nacionales oprimidas por la secular política de la monarquía.» ${ }^{22}$

La identificación de la causa republicana con la causa general de la democracia era una construcción promovida por el gobierno republicano que no sería abandonada en tanto el conflicto fratricida no encontrara finalización. En este sentido, el campo cultural fue un espacio privilegiado para el desarrollo de los debates y la propaganda destinada a destacar la urgente necesidad de involucramiento general en una lucha sin cuartel que se libraba entre la democracia y el autoritarismo. Esta operación de reconocimiento de la situación y de la conformación de los bandos antagónicos alentó entre los comunistas la necesidad de promocionar una disociación entre la causa republicana y la revolución socialista. ${ }^{23}$ El Segundo Congreso Internacional de Escritores, tal como lo destacaba Raúl González Tuñón, guardaba una doble consideración, pues además de reafirmar el compromiso de los intelectuales antifascistas que en 1935 se habían dado cita en París para conformar la Asociación Internacional de Escritores en Defensa de la Cultura, tenía la particularidad en esta nueva oportunidad de llevarse a cabo en Valencia. ${ }^{24}$ La estrategia del comunismo y del

${ }^{21}$ El propio José Díaz, en un discurso pronunciado el 9 de mayo de 1937 en Valencia, se había ocupado de dejar públicamente en claro el motivo de fuerza que guiaba el comportamiento del PCE a lo largo del conflicto, expresado en la concatenación lógica de triunfo de la guerra seguido de «revolución popular»-ya no «obrera y campesina»-. José Díaz, Qué somos y qué queremos los comunistas, Editorial F. P., Buenos Aires, 1937. Reproducido por el PCA en Nuestra Revista, agosto de 1937, año I, N. ${ }^{2}$ 2, pp. 15-22.

22 «Apoyemos a la España democrática», Hoy, año I, N.` 1, 17/9/1936, p. 5.

${ }^{23}$ Un ejemplo nacional de esta posición en el folleto de Luis V. Sommi, «La unión del pueblo contra el fascismo: Informe presentado al IX Congreso del Partido Comunista Argentino», enero de 1938 .

${ }^{24}$ Manuel Aznar Soler y Luis Mario Schneider (Eds.), II Congreso Internacional de Escritores Antifascistas (1937). Volumen III. Ponencias, documentos y testimonios, Laia B, Barcelona, 1979, pp. 40-41. 
gobierno español consistía en demostrar la fortaleza del campo antifascista dentro del país al mismo tiempo que se avanzaba en la señalización del alcance mundial de la contienda. Esta maniobra era respaldada por la conservación y profundización del carácter multitudinario de las fuerzas políticas integradas en el gobierno republicano. Cuando en mayo de 1937 se inauguró en París, con motivo de la promoción de la paz internacional, la Exposición Internacional «Arts et Techniques Dans la Vie moderne», el pabellón destinado a la República española se cuidó de mantener aquella representación de la unidad española que el gobierno de Frente Popular intentaba generar en el extranjero. ${ }^{25}$ Las corrientes estéticas afines a los distintos nucleamientos políticos que integraban el gobierno republicano estuvieron presentes en el pabellón español.

Dentro de la serie de prácticas que encontró a los intelectuales de izquierda comprometidos con la defensa de la causa republicana ocupa un lugar destacado el papel de Cayetano Córdova Iturburu. En calidad de corresponsal del diario Crítica, Córdova Iturburu parte hacia España desde Buenos Aires el 15 de febrero de 1937 y regresa a la Argentina seis meses más tarde, publicando posteriormente un libro de propaganda pro-republicana en el cual se hacía eco de las estrategias en boga destinadas a politizar sin polemizar con potenciales aliados. En concreto, en su perspectiva era el Partido Comunista el que había logrado impulsar y realizar la unidad en el Frente Popular a partir de su «tenaz prédica unitaria» ${ }^{26}$. $\mathrm{Pu}$ blicado en Buenos Aires en plena contienda, son evidentes los recaudos tomados a la hora de no concentrar todo el heroísmo en el desempeño unilateral de los comunistas españoles. Antes bien, se notan los esfuerzos por evitar alusiones explícitas al comunismo. Las referencias son a la unidad antifascista reunida en el Frente Popular. Los personajes de sus recuerdos no son los grandes políticos y militares - Modesto, Líster, el «Campesino», Mera, la «Pasionaria», el comandante Durand, Galán, José Díaz, Jesús Hernández, el general Miaja, apenas son enumerados en la introducción-, sino hombres corrientes, soldados desconocidos que proporcionan las anécdotas de sacrificio de las que se nutre el libro. Córdova Iturburu traducía en términos pluralistas y no-partidistas lo que el comunismo español propuso desde temprano y nunca abandonó en todo el tiempo en que se extendió el conflicto: mando único, sí, pero en manos del PCE.

25 Cf. David Priestland, Bandera roja. Historia política y cultural del comunismo, Crítica, Barcelona, 2010, pp. 191-193.

${ }^{26}$ Cayetano Córdova Iturburu, España bajo el comando del pueblo, op. cit., p. 142. 
Los esfuerzos republicanos por mostrar al mundo un gobierno democrático y pluralista, no ejercido por fuerzas políticas transgresoras de las leyes de propiedad vigentes, fueron reproducidos por los núcleos de ayuda a España en la Argentina, incluyendo la FOARE. De este modo, La Nueva España, órgano de prensa del Comité de Ayuda al Gobierno Español del Frente Popular, se esforzaba en explicar que la defensa de la República era obligación de todos los hombres y mujeres respetuosos del liberalismo, y que por lo tanto el argumento esgrimido por los enemigos del gobierno español respecto de una supuesta lucha contra el comunismo era una proverbial falacia. ${ }^{27} \mathrm{La}$ avanzada franquista no estaba dirigida a eliminar el comunismo, sino que tenía por todo propósito la aniquilación de la democracia. La clase media española no había caído presa de las tergiversaciones que promovía la unidad de derechas miliarfascista-clerical, y había comprendido a tiempo que no se avecinaban sobre la península ningún proceso de transformación anárquica ni ninguna «ola de terror rojo». Los comunistas - españoles, argentinos y soviéticos - estaban dando sobradas muestras de que velarían porque así fuera.

Pero el gobierno argentino de todas formas había identificado el pro-republicanismo en el país con la causa de los bolcheviques. El PCA, que había sido proscrito al poco tiempo de producido el derrocamiento de Yrigoyen, sumaba un nuevo obstáculo con la legislación anticomunista. Las actividades del partido quedaban relegadas a la clandestinidad, lo que no le impediría dar muestras de una encomiable habilidad para permear en el conjunto de la sociedad argentina. El bloque antidemocrático que se hizo con el poder en el país durante la llamada Década Infame contaba con la colaboración de la Unión Cívica Radical (partido de la clase media argentina), de los socialistas y de los líderes anarcosindicalistas, quienes entendían que se había producido un «retorno a la normalidad ${ }^{28}$ con el traspaso del Poder Ejecutivo del gobierno golpista de José F. Uriburu al gobierno fraudulento de Agustín P. Justo. Bajo la óptica comunista, las fuerzas democráticas eran cómplices de la represión estatal que caía sobre el movimiento obrero y que incluía el encar-

27 Marcial Edalb, «Hay que proclamar la verdad sobre España», N. ${ }^{\circ} 22$, La Nueva España, 2/1/1937, p. 1.

28 «Resolución sobre situación y tareas del Partido Comunista de la Argentina», Buenos Aires, febrero de 1932, Biblioteca del Congreso de la Nación Argentina, Archivo Centro Cultural de la Cooperación, 329.15(82)PCa18. 
celamiento a lo largo de todo el país de 2.000 trabajadores $^{29}$. La táctica de «clase contra clase» y sus ataques al socialismo y al radicalismo cayeron inmediatamente en desuso cuando se impuso la orientación de «frente popular» que se hallaba en desarrollo en España, en donde se había decidido la «acción unitaria de ambos partidos [PCE y PSOE) en el gobierno, en todos los órganos de poder, en los sindicatos, en el ejército, en la dirección de la industria, así como presentación conjunta a las elecciones parlamentarias y municipales» ${ }^{30}$. El PCE había optado por integrar el gobierno pluralista de Francisco Largo Caballero y posteriormente la IC había consentido su decisión. ${ }^{31}$ La orientación frentepopulista pasó a ser, a comienzos de 1936, la vía más apropiada para luchar localmente «contra el fraude y por las libertades democráticas, avasalladas ya en la Pcia. de Buenos Aires por los fresquistas y uriburistas y que amenazaban a todo el país» ${ }^{32}$.

Por entonces tenía lugar un intento de unidad promovido por el Partido Socialista Argentino en su relación con la Unión Cívica Radical y el Partido Demócrata Progresista, del cual quedaba afuera el PCA. Los demás partidos que habían logrado conservar su carácter legal prefirieron no correr los riesgos que suponía estrechar vínculos con una organización política proscrita y se manifestaron reticentes a aceptar la participación de los comunistas. ${ }^{33}$ El carácter ilegal del PCA era el motivo de mayor significación para su aislamiento con los partidos legatarios, pero también es evidente que las acusaciones recientemente vertidas acerca del «fascismo» de la segunda presidencia de Yrigoyen y de la política «socialtraidora» de los socialistas, contribuyeron a aumentar las reservas de la UCR

29 « Contra la Dictadura Sanguinaria!», volante del Comité Regional de la Capital, Buenos Aires, enero de 1932, Biblioteca del Congreso de la Nación Argentina, Archivo Centro Cultural de la Cooperación, 329.15(82)PCa19.

30 Resolución del Presidium del Comité Ejecutivo de la IC, 20 de septiembre de 1937 (en itálicas en el original). Citado por Frank Schauff, La victoria frustrada. La Unión Soviética, la Internacional Comunista y la Guerra Civil Española, Barcelona, Debate, 2008, p. 152.

31 Fernando Hernández Sánchez, Guerra o revolución. El Partido Comunista de España en la guerra civil, Barcelona, Crítica, 2010, pp. 107-110.

32 «Solidaridad con el Frente Popular Español», volante del Partido Comunista de la Argentina (Barrio Once), Biblioteca del Congreso de la Nación Argentina, Archivo Centro Cultural de la Cooperación, 329.15(82)PCa22.

${ }_{33}$ Cf. Alberto Ciria, Partidos y poder en la Argentina moderna (1930-1946), Buenos Aires, Hyspamérica, 1986, pp. 69-79, 189. 
y el PSA respecto de un potencial frente común con el comunismo. ${ }^{34} \mathrm{Si}$ la guerra fratricida dio paso en España a «una atmósfera de necesaria unidad eufórica del antifascismo, pero no llevó a una identificación que pudiera eliminar las distintas formas de comprender las relaciones políticas conflictivas que habían mostrado el nivel de su hostilidad en los años anteriores ${ }^{35}$, lo cierto es que estas mismas limitaciones se hicieron presentes en la sección argentina de la IC. En efecto, la táctica comunista de clase contra clase dificultó el proceso de construcción antifascista no solo en España, si no también en la Argentina. El PCA no contó más que con el apoyo abierto del Partido Socialista Obrero en las negociaciones para la conformación de una Alianza Democrática. El líder de la IC, el búlgaro Georgy Dimitrov, se interesó por el proyecto de unidad política de fuerzas democráticas que se estaba dando en la Argentina. Tomando como parámetros los casos de Francia y España, pero señalando en todo momento la necesidad de no perder de vista ni un instante las condiciones específicas de la sociedad argentina, Dimitrov consentía el avance de las relaciones entre el comunismo y los partidos legatarios. ${ }^{36}$

La Guerra Civil española puso a prueba la capacidad del PCA para romper la circunscripción del obrero comunista convencido. En este sentido, proliferaron en la Argentina bajo su auspicio numerosos comités de ayuda regionales entre los que se destacó por su importancia, pero también por ser uno de los pocos casos estudiados, el Centro Republicano Español de Mar del Plata, fundado en 1929, que en sus orígenes bregó por la instauración de la República. ${ }^{37}$ Una vez estallado el conflicto fratricida, el Centro Republicano Español marplatense dio forma a una Subcomisión de

${ }^{34}$ Cf. Marilú Bou, op. cit., p. 12; Juan Luis Carnagui, «La ley de represión de las actividades comunistas de 1936: miradas y discursos sobre un mismo actor», en Revista Escuela de Historia, año 6, vol. 1, N. ${ }^{\circ}$ 6, 2007, pp. 161-178.

35 Julián Ferrán Gallego, La crisis del antifascismo. Barcelona, mayo de 1937, Barcelona, Debolsillo, 2008, p. 233. Urge recordar que los comunistas españoles se habían opuesto a integrar en 1934 las Alianzas Obreras promovidas por el PSOE, tras considerar que debían conformarse expresiones autóctonas de los soviets rusos. Fernando Hernández Sánchez, Comunistas sin partido. Jesús Hernández. Ministro en la Guerra Civil, disidente en el exilio, Madrid, Raíces, 2007, p. 52

${ }^{36}$ La posición del dirigente de la IC a este respecto está documentada en Carta del Secretariado del CE de la IC, 29 de junio 1937, Carta del Secretariado del CE de la IC, 2 de julio de 1937 e Informe de Dimitrov del 7 de julio de 1937, [En ruso], Archivo de la Internacional Comunista, Biblioteca del Congreso de la Nación Argentina (en adelante Archivo IC, BCNA), microfilm rollo (r.) 1, sección (s.) 13.

37 Lidia Bocanegra, «La ayuda argentina a la República española», op. cit., p. 2. 
Socorro a España, que pasó a actuar supeditada a la Asociación Amigos de la República Española. Los comités de ayuda a España, a su vez, contaron con un destacado aporte del sector femenino, que implicó una ruptura respecto del comportamiento social tradicionalmente ocupado por la mujer argentina. ${ }^{38}$ La quiebra radical del rol de las mujeres españolas contribuyó a animar esta transformación, expresada colaboración femenina a través de la organización de numerosas colectas. El PCA, como fundador y gestor más importante de los comités de ayuda en Argentina participó, de esta manera y sin que formara parte de una proposición meditada, en nuevas formas de experiencias liberadoras de las mujeres obreras y de clase media.

La Comisión Pro Presos Sociales, encabezada por el PCA y alentada desde su formación por el Socorro Rojo Internacional, contaba con una experiencia de años en la que la defensa de los anarquistas españoles Ascaso, Durruty y Jover en 1927, si bien había provocado el malestar en el anarquismo argentino, constituyó un hito. ${ }^{39}$ En ese entonces se había designado a Luis Riccardi para que participara en las reuniones del Socorro Rojo Internacional. ${ }^{40}$ Los comunistas argentinos nunca dejaron de protestar ante los procesos abiertos contra detenidos políticos tanto de Argentina como de España. Por su parte la FOARE, principal organismo de colaboración con la causa republicana, ${ }^{41}$ quedó rápidamente bajo la esfera de influencia del PCA.

38 Santiago Allende, Federico Boido, Eugenia Galiñanes, Leandro Gamallo, «La Guerra Civil Española en la Argentina: Una mirada desde las publicaciones periódicas de la colectividad española en el país», en $V$ Encuentro de Bibliotecas de Colectividades, Biblioteca Nacional de la República Argentina, Hemeroteca, Buenos Aires, 2010, pp. 15-16. [Tomado de: http://www.bn.gov.ar/descargas/recursos/colectividades/7-guerracivil.pdf. Ultimo acceso: $24 / 04 / 2012]$

${ }^{39}$ Cf. Osvaldo Bayer, Los anarquistas expropiadores y otros ensayos, Booket, Buenos Aires, 2007, p. 51.

${ }^{40}$ Reunión del Comité Central, 18 de marzo de 1927, p. 1, Archivo IC, BCNA, r. 4, s. 31.

${ }^{41}$ El pequeño grupo de federaciones de carácter nacional que fueron formados en la Argentina se completó con la Asociación Amigos de la República Española y la Comisión Coordinadora de la Ayuda a España en Argentina (Coordinadora); la FOARE demostró ser la más dinámica de las tres federaciones de carácter nacional. También existió desde temprano una gran cantidad de comités provinciales de ayuda a la República. Asimismo es importante mencionar que el desarrollo de campañas para ayudar a España y la formación de organismos para coordinar las tareas fueron promovidas entre los partidos comunistas nacionales desde el Comité Ejecutivo de la IC entre fines de 1936 y otoño de 1938. Cf. Daniel Kowalsky, La Unión Soviética y la guerra civil española. Una revisión crítica, Crítica, Barcelona, 2004, p. 99. 
Asimismo, el PCA se mostró junto a los anarquistas como un eficaz reclutador de voluntarios, principalmente entre las masas trabajadoras. ${ }^{42} \mathrm{El}$ desarrollo de esta actividad debía ser realizado bajo un doble nivel de seguridad, puesto que, por una parte, no contaba con el consentimiento del gobierno nacional, en tanto que, por otro lado, debía ser llevado a cabo con un filtro riguroso aplicado a los aspirantes. En este sentido, vale señalar que, en su carta al CE de la IC de septiembre de 1936, Codovilla comunicaba que con el propósito de evitar la infiltración de elementos fascistas en las filas de la resistencia, todo aquel que quisiera unirse al ejército republicano debía «ser recomendado por un partido o una organización aprobada por el Frente Popular y el Comité del Frente Popular» ${ }^{43}$.

Más allá de este trabajo clandestino, fue la intensa participación en los movimientos de solidaridad legalizados lo que, durante este periodo, permitió al proscrito PCA tomar de manera eficiente contacto con las masas. ${ }^{44} \mathrm{Su}$ intervención en el conflicto español les permitió a los comunistas argentinos interactuar en la sociedad argentina desde una posición activa que, dado el contexto político nacional, no habrían podido conseguir por otros medios. Pero, a su vez, se ha de señalar que si el comunismo logró erigirse en el gran organizador de la solidaridad con la República, ello se debió en parte al hecho de que ejercía un hábil pragmatismo en otro ámbito legalizado: la práctica sindical.

${ }^{42}$ Así se desprende de las fichas consignadas por los voluntarios argentinos en Archivo Centro de Documentación e Investigación de la Cultura de Izquierdas en Argentina, AR CEDINCI COL-12-Brigadas Internacionales [copias correspondientes a documentos del Archivo Estatal Ruso de Historia Socio-Política, fondo 545, inventario 6]. Esta preponderancia entre los voluntarios de miembros de la clase obrera no fue una particularidad del caso argentino, sino que se registró también en los casos de Estados Unidos, Canadá y países de Europa. Cf. Helen Graham, The War and its Shadow. Spain's Civil War in Europe's Long Twentieth Century, Brighton-Chicago-Toronto, Sussex Academic Press, 2015, p. 77.

43 V. Codovilla, «Doklad tov. KODOVIL'IA o polozhenii v Ispanii», 22/9/1936, Komintern i grazhdanskaia voina v Ispanii. Dokumenty, Moskva, Nauka, 2001, p. 132 [la traducción es nuestra].

44 «Entre 1936 y 1939, los comunistas vincularon sus propias posibilidades de expansión a la acción potencial dentro del movimiento de solidaridad. No fueron los únicos. [...] Pero ninguna agrupación se planteó una política tan consciente y elaborada como el PCA y nadie fue tan eficaz en su consecución». Mónica Quijada, Aires de República, aires de Cruzada, op. cit., p. 164. 


\section{EI Frente Popular en el programa de acción del PCA}

La IC había dispuesto en 1928 la implementación de una «política de sindicalismo doble» ${ }^{45}$, que consistía en que cada una de sus secciones conformara centrales obreras disociadas de los grupos obreros ya existentes. Tomando en consideración estas prerrogativas, el PCA había dado forma en 1929 al Comité de Unidad Sindical Clasista (CUSC). ${ }^{46}$ La situación política de aislamiento, ilegalidad y represión que atravesaba el PCA implicó en 1935 el abandono del trabajo que hasta entonces los comunistas habían estado realizando en solitario dentro del CUSC. La Confederación General del Trabajo (CGT) nucleaba al momento de estallar la Guerra Civil española a 262.630 obreros. ${ }^{47}$ La aparición de la CGT había sido originalmente considerada por el PCA como la organización de una fuerza sindical de traición al movimiento obrero, aliada natural de la junta militar fascista que había llegado al poder tras la caída de Yrigoyen, ya que su programa de reformas tenía por finalidad «convertir los organismos sindicales en simples resortes del aparato del Estado capitalista, opresor de los obreros» ${ }^{48}$. No obstante, en respuesta a la política de cooperación con la izquierda democrática impulsada por la IC a partir de su VII Congreso, el PCA determinó en la ciudad de Rosario en los días 2 a 4 de agosto de 1935 que había llegado la hora de disolver su propia central, el CUSC, para ingresar en las filas de la CGT a aquellos sindicatos que dominaba. ${ }^{49}$ La primera acción de la CGT estuvo centrada en la necesidad de asistir a los obreros que habían sido - y continuaban siendo - detenidos por la

45 Robert J. Alexander, El movimiento obrero en América Latina, Roble, México, 1967, p. 61.

${ }^{46}$ Cf. Hernán Camarero, «Partido y sindicato en la Argentina. La actuación de los comunistas en los gremios hasta mediados de los años treinta», Ciclos en la historia, la economía y la sociedad, vol. 20, N. 39, enero/junio, 2012.

47 Joel Horowitz, «El movimiento obrero», Alejandro Cattaruzza (Dir.), Crisis económica, avance del estado e incertidumbre política (1930-1943), tomo 7, Sudamericana, Buenos Aires, 2001, p. 260.

48 «El «programa mínimo» de la C.G.T. reformista de la Argentina (Luis Cecchini)», El Trabajador Latinoamericano, año III, N. ${ }^{40-41, ~ m a y o-j u n i o ~ d e ~ 1931, ~ p . ~} 56$.

49 Sin embargo, los gremios ligados al PCA no pudieron integrar la CGT hasta el cambio de manos de su dirección desde los sindicalistas a los socialistas, ocurrido en 1936, puesto que era grande la desconfianza sobre el respeto de los comunistas hacia el principio de no-partidismo que regía la vida de la central. Cf. Hernán Camarero, A la conquista de la clase obrera. Los comunistas y el mundo del trabajo en la Argentina, 1920-1935, Siglo XXI, Buenos Aires, 2007, p. 211. 
policía en función de la orden dictaminada por el Poder Ejecutivo nacional para amedrentar al trabajo asalariado que protestaba por los efectos de la crisis universal del capitalismo..$^{50}$ Quedaban atrás los días en los que el comunismo denunciaba a la CGT por prestar su apoyo tácito al gobierno militar para llevar a cabo su campaña de deportaciones y encarcelamientos de luchadores sociales. ${ }^{51}$

Al interior de la CGT se había producido una profunda compulsa por la decisión original de mantener a la central obrera alejada de todo partido político y grupo ideológico. Promediando la década, los socialistas comenzaron a cuestionar el apoliticismo taxativo del sindicalismo en detrimento de una orientación de aproximación a las fuerzas democráticas que clamaban por el restablecimiento del orden constitucional. ${ }^{52}$ Dicha operación de traspaso ya había sido operada en las organizaciones de trabajadores de España y Francia, bajo el marco de los frentes populares, experiencia que, sin lugar a dudas, ejerció una influencia fundamental en la reformulación estratégica del Partido Socialista Argentino y de otros partidos políticos..$^{53}$

Tal como señala Nicolás Iñigo Carrera, al promediar el decenio de 1930 la clase obrera argentina se da para sí un programa de acción en el cual requiere del acuerdo con ciertas fracciones de la burguesía. ${ }^{54} \mathrm{La}$ primera de estas alianzas sociales, surgida al calor de la huelga general que tuvo lugar en Buenos Aires los días 7 y 8 de febrero de 1936 - origen de la gran manifestación a nivel nacional del $10^{\circ}$ de mayo-, tomó muy pronto el cariz de una alianza política. Los afiliados al PCA adscribieron a la estrategia general que por entonces asumía la clase obrera organizada

50 Sebastián Marotta, El movimiento sindical argentino. Su génesis y desarrollo. Tomo III. Período: 1920-1935, Calomino, Buenos Aires, 1970, pp. 318-320.

51 Cf. «La lucha contra las deportaciones en la Argentina», El Trabajador Latinoamericano, año IV, ${ }^{\circ}{ }^{\circ} 44-45$, noviembre-diciembre de 1931, pp. 6-7.

52 Samuel L. Baily, Movimiento obrero, nacionalismo y política en la Argentina, Hyspamérica, Buenos Aires, 1985, pp. 67-69. Hiroshi Matsushita, Hiroshi, Movimiento obrero argentino 1930/1945. Sus proyecciones en los orígenes del peronismo, Siglo Veinte, Buenos Aires, 1983 p. 146.

53 Con anterioridad a las prácticas de frente popular de Europa occidental, «los actores políticos de esta etapa argentina, se rehusaban a asociar las amenazas que pesaban sobre el futuro de la democracia en el mundo con los dilemas que ésta afrontaba en la Argentina». Tulio Halperin Donghi, La Argentina y la tormenta del mundo. Ideas e ideologías entre 1930 y 1945, Siglo XXI, Buenos Aires, 2004, p. 15.

${ }^{54}$ Nicolás Iñigo Carrera, «Lucha Democrática de la Clase Obrera Argentina en las Décadas de 1930 y 1940», Crítica de Nuestro Tiempo, 6, Julio-Agosto-Septiembre 1993, p. 139. 
en la intención por enfrentar los embates de un capitalismo en fase de recuperación, estrategia que consistía en "penetrar en el sistema institucional y lograr las mejores condiciones dentro del sistema económico y social vigente, sin trascenderlo» ${ }^{55}$.

Es esta realidad de lucha contra el nuevo orden antiliberal lo que conduce al movimiento obrero argentino, en la comprensión de problemáticas comunes, a tomar partido por la defensa de la República española. El año de 1935 supuso una importante reactivación del movimiento obrero que se tradujo en la concreción de 69 huelgas en las que participaron alrededor de 52.000 trabajadores ${ }^{56} \mathrm{~A}$ partir de la década de 1930 el peso de la dirección de los sindicatos había ido traspasando de los servicios a la industria y la construcción..$^{57}$ Desde que los reclamos de los albañiles concluyen en la huelga exitosa de diciembre de 1935 y enero de 1936, los comunistas, que habían sido los conductores de la lucha y que en adelante se convierten en los forjadores de la multitudinaria Federación Obrera Nacional de la Construcción, ganan considerable prestigio entre los obreros. Esta federación recibió afiliados prácticamente a lo largo de todo el país. ${ }^{58}$ A partir de 1937, el de la construcción demostrará ser el gremio más dinámico del movimiento obrero, lo que se verá reflejado en el creciente número de cotizantes registrado en sus filas ${ }^{59}$ Esto situaba al comunismo en una posición favorable al momento de ejercer una fuerte influencia en el planteo de directrices para hacer frente desde la Argentina a la realidad española, actividad que, simultáneamente, posibilitaba al PCA cooptar mayores apoyos en los mundos del trabajo. Así, las agitaciones político-sociales expresadas a través de las campañas de lucha gremial y de lucha antifascista conformaban un mismo proceso dialéctico.

En el acto convocado por la CGT con motivo del 1..$^{\circ}$ de mayo en 1936 se desempeñaron como oradores el sindicalista José Domenech, el socialista Mario Bravo, el radical Arturo Frondizi y el demoprogresista Lisandro de la Torre, en tanto que al PCA no se le otorgó un lugar para dirigirse

55 Idem, p. 161.

56 Hernán Camarero, A la conquista de la clase obrera, op. cit., p. 210.

57 Julio Godio, Héctor Palomino, Archim Wachendorfer, El movimiento sindical argentino (1880-1987), Puntosur, Buenos Aires, 1988, p. 35.

58 Joel Horowitz, «El movimiento obrero», op. cit., p. 265.

59 Cf. Celia Durruty, Clase obrera y peronismo, Pasado y Presente, Buenos Aires, 1969, pp. 51-ss. 
a las masas congregadas. ${ }^{60}$ Un año más tarde la situación de los comunistas iba a ser muy distinta. El 3 de agosto de 1936 el Comité Ejecutivo de la IC adoptó por primera vez una resolución para que fuera organizada una intensa campaña de apoyo a los defensores de la causa republicana, resolución que fue ratificada y reforzada en septiembre cuando Codovilla manifestó la necesidad de «apremiar un poco la solidaridad internacional, no sólo de palabra, sino con algo más concreto» ${ }^{61}$. En la Argentina todo un conglomerado de organizaciones sindicales y organismos de ayuda, en conjunción con un grupo de partidos democráticos, preparó una gran manifestación de solidaridad con España para el 1. ${ }^{\circ}$ de Mayo de $1937 .{ }^{62}$ En este activismo el PCA se mostraba como el principal promotor.

El Comité Central del PCA anunciaba al promediar el año de 1937 el carácter decisivo que habrán de revestir los meses siguientes en el desarrollo de la Guerra Civil española y llamaba a reforzar de manera considerable la colaboración destinada al pueblo español. ${ }^{63}$ El PCA reclamaba que fueran reconocidos el gobierno constitucional de España y su libertad de comercio, incluyendo el derecho a la compra de armamentos corriente para cualquier gobierno legítimo. Se debía luchar por la expulsión de todo elemento nazifascista extranjero y por el respeto de la seguridad internacional según el derecho trazado por la Sociedad de Naciones. También era importante en lo inmediato proceder a singularizar y difundir la posición soviética respecto del conflicto. Estas acciones debían ser acompañadas por una potente campaña de propaganda y agitación en apoyo del gobierno de Frente Popular. Al llevar la información del conflicto español a las masas se debía hacer constar de manera clara y concisa la diferencia existente entre la excepcional situación ibérica y las condiciones políticas

60 Julio Godio, El movimiento obrero argentino (1930-1943), op. cit., p. 212.

${ }^{61}$ Protocolo ECCI N. ${ }^{\circ}$ 74, septiembre de 1936, RGASPI, f. 495, op. 18, del. 1135, 1. 6. Citado por Daniel Kowalsky, «La Unión Soviética y las Brigadas Internacionales», Ayer, N. ${ }^{\circ} 56,2004$, p. 101.

${ }^{62} \mathrm{Cf}$. «Una gran manifestación de solidaridad con España se realizará el 1o. de Mayo», La Nueva España, N. 54, 25/4/1937, pp. 1, 3; «Los comités de ayuda a España engrosarán la manifestación. La solidaridad con España será consigna básica», La Nueva España, N. ${ }^{\circ}$ 55, 29/4/1937, p. 1; «El 1o. de mayo de 1937 debe ser solidaridad con España leal», La Nueva España, N..$^{\circ}$ extraordinario en solidaridad con los trabajadores españoles, $1 / 5 / 1937$, p. 1. El PCA volvería a revelarse como un organizador central en el acto de la CGT por el Día del Trabajador en 1938. Cf. Luis V. Sommi, ; Unidad! Por el pan, la libertad y la paz del pueblo argentino, Buenos Aires, Partido Comunista Argentino, 1938.

${ }_{63}$ Resolución del CC del PCA para la ayuda a la España republicana, 10 de julio de 1937, Archivo IC, BCNA r. 1, s. 13 [En francés]. 
vigentes en la Argentina. El PCA seguía el curso señalado por Dimitrov: la Argentina no era España, y por lo tanto sus partidos comunistas debían darse programas de acción distintos. ${ }^{64} \mathrm{La}$ ayuda material era sumamente importante. Esta se componía especialmente de la colecta de fondos que debían ser cambiados por bienes de consumo en forma urgente para su inmediato envío. No obstante, la herramienta de mayor fuerza en este sentido la constituían los padrinazgos, los que podían adquirir diversas formas: las ciudades sobre otras ciudades, los sindicatos sobre las unidades militares, los intelectuales sobre los hospitales.

Asimismo, la campaña de propaganda ideológica conducida por el PCA rindió ingentes frutos. La actividad de los comités de ayuda fue extremadamente efectiva. Mónica Quijada argumentó con abundancia de datos que, partiendo del índice poblacional de la época, la Argentina fue el país en donde se lograron las mayores recaudaciones de dinero para contribuir con la causa republicana. De hecho, a partir de enero de 1937, La Nueva España estuvo en condiciones materiales, dada su elevada tirada (basada en parte en el éxito de su llamado a que cada suscriptor debía hacer un nuevo suscriptor), de dejar de ser semanario para pasar a adquirir aparición bisemanal. En definitiva, la FOARE, que se regía por los dictámenes de la IC, fue registrando un crecimiento progresivo en la organización de las actividades tocantes a la colaboración con la República. Las actividades de difusión fueron impulsadas con especial energía por los comunistas desde la FOARE. Desde el trabajo de organización y centralización de la ayuda para España realizado por la FOARE, la dirección comunista logró con particular pericia «atraerse tanto a los grupos independientes - es decir, los comités que operaban libres de las tutelas de los partidos - como de los que estaban bajo el ala de los anarquistas de la Coordinadora o de la red republicano-socialista, es decir, del Centro Republicano Español y el Partido Socialista Argentino» ${ }^{65}$. A partir de este desequilibrio, toda colaboración para España estuvo mucho más mediada

${ }^{64}$ Carta del Secretariado del CE de la IC [firma Dimitrov], 29 de junio de 1937, Archivo IC, BCNA, r. 1, s. 13 [En ruso].

${ }^{65}$ Silvina Montenegro, op. cit., p. 80. Esto no impediría, de todas formas, el surgimiento de algunas discrepancias y delaciones respecto de la naturaleza de las acciones de colaboración comunista con la causa republicana. En este sentido, Joaquín Coca, uno de los fundadores del Partido Socialista Obrero, advertía que los emprendimientos pro-republicanos constituían «el negocio político y pecuniario que el PC explotaba al por mayor». Joaquín Coca, Quinta columna bolchevique, s/e, Buenos Aires, 1940, s/p. 
por las regulaciones y disposiciones comunistas, expresadas a través de la conducción de su partido.

\section{La dirección del PCA en tiempos de represión}

En el contexto de represión general impuesto por el gobierno militar durante la Década Infame, los miembros del PCA se llevaban la peor parte. La agrupación civil liderada por Carlos Silveyra que se dio a conocer en 1932 bajo el nombre de Comisión Popular Argentina contra el Comunismo, se arrogó la misión de realizar actividades de presión al gobierno nacional para reclamar por la imposición de todo un arsenal de medidas que contribuyeran a eliminar la presencia del comunismo en el país. ${ }^{66}$ Por su parte, la ley de represión contra el comunismo que con tanto ahínco habían promocionado el legislador conservador bonaerense Matías Sánchez Sorondo y el gobernador salteño Carlos Serrey, fue finalmente aprobada por la Cámara de Senadores en noviembre de 1936. ${ }^{67}$ Los comunistas argentinos lograron incorporar las represiones sufridas localmente por las fuerzas democráticas dentro de un mismo movimiento sistemático internacional y convirtieron las confrontaciones españolas en el paradigma de la coyuntura del momento. Así, la ley de Sánchez Sorondo quedó adherida al fascismo europeo. A través de la FOARE se procedió a dar una canalización efectiva a esta acción denunciatoria. Por mencionar

${ }^{66}$ Mariela Alejandra Rubinzal, «iA ganar las calles! Movilizaciones nacionalistas en el período de entreguerras», en Mirta Zaida Lobato (Ed.), Buenos Aires. Manifestaciones, fiestas y rituales en el siglo XX, Biblos, Buenos Aires, 2011, pp. 135-136.

${ }^{67}$ La Ley de Represión del Comunismo había empezado a circular como proyecto en 1932 e inmediatamente generó el rechazo uniforme del movimiento obrero, plasmado por los comunistas en las declaraciones emitidas por el Socorro Rojo Internacional y el Comité de Unidad Sindical Clasista. Cf. Mercedes López Cantera, «Detrás del debate. La cuestión comunista y la criminalización en la ley de represión al comunismo de 1936», Contenciosa, Año II, N. ${ }^{\circ} 3$, segundo semestre 2014; N. Iñigo Carrera, «La huelga general política de 1932: descripción de los inicios de un ciclo en la historia de la clase obrera argentina», en Programa de Investigación sobre el Movimiento de la Sociedad Argentina (PIMSA), Documentos y Comunicaciones, año V, N. ${ }^{\circ}$ 5, 2002, p. 57. Dos estudios ineludibles a la hora de realizar una indagación de la radicalización de la derecha en la Argentina durante la primera parte del siglo XX son: Sandra McGee Deutsch, Contrarrevolución en la Argentina, 1900-1932. La Liga Patriótica Argentina, Universidad Nacional de Quilmes, Buenos Aires, 2003; Susan McGee Deutsch, Las derechas. La extrema derecha en la Argentina, Brasil y Chile, 1890-1939, Universidad Nacional de Quilmes, Buenos Aires, 2005. 
un caso emblemático, cuando se decidió la publicación de 10.000 ejemplares conteniendo los discursos que los senadores Lisandro de la Torre y Mario Bravo pronunciaron en la cámara alta del Congreso de la Nación rechazando las ideas del conservador argentino, a quien se le dio el seudónimo de «apologista de Burgos», se decidió que la totalidad de lo recaudado por la venta de los libros sería destinado a la ayuda del proletariado español. ${ }^{68}$

La nueva legislación represiva «era lo suficientemente ambigua como para impedir también la actividad en favor de la República Española» ${ }^{69}$. Cuando se produjo el levantamiento franquista, el Ministerio de Relaciones Exteriores y Culto de la Argentina se hallaba dirigido por Carlos Saavedra Lamas. Como representante directo de los intereses de la oligarquía argentina, estrechamente vinculados a los de la clase alta británica, Saavedra Lamas se apresuró a adherir la política internacional argentina a las disposiciones emanadas por el Comité de No-Intervención. Si bien es cierto que, en vistas de las consideraciones ideológicas derechistas fuertemente anticomunistas de los miembros del fraudulento gobierno argentino, la prescindencia era el mejor resultado que desde la perspectiva del gobierno legal de España se podía obtener, esto de ninguna manera impidió al gobierno nacional activar sus dispositivos de control sobre las prácticas políticas civiles. ${ }^{70}$ La oposición al oficialismo, contraria también a las simpatías de este último hacia los sublevados españoles, fue violentamente silenciada bajo pretextos basados en la necesidad de combatir al comunismo. Objeto de la misma imposición coercitiva fue el primer contingente de refugiados españoles que llegan al país en septiembre de 1936, asociados por el estado nacional con la «España roja». Entre otras restricciones públicas, se limitaban en forma drástica los mítines políticos, quedando supeditada la realización de los mismos a la posición ideológica de los grupos organizadores. ${ }^{71}$ De tal suerte, el propio gobierno argentino

68 «Ya está en prensa el libro que contiene los discursos de los senadores De La Torre y Bravo, contra la represión de las ideas», La Nueva España, N. ${ }^{\circ} 23,7 / 1 / 1937$, p. 3.

69 Raanan Rein, «Otro escenario de lucha», op. cit., p. 34.

70 Mónica Quijada, Aires de República, aires de Cruzada, op. cit., pp. 25 y 35.

71 En la ciudad de Mendoza se permitió a principios de diciembre de 1936 una reunión de apoyo al franquismo; al día siguiente un encuentro de solidaridad con los republicanos pautado por el Partido Socialista fue vedado por presuntas implicaciones comunistas. Ernesto Goldar, op. cit., p. 31. Las prohibiciones en torno de las manifestaciones pro-republicanas iban a adquirir formas insospechadas. Cuando el Comité Femenino Pro Ambulancia logró reunir los fondos suficientes para efectivizar el propósito de su existencia, se planeó 
fue el que se encargó de promover la identificación de cualquier manifestación pro-republicana con toda una serie de derivas del comunismo internacional. Sin embargo, durante casi todo el tiempo por el que se prolongó la contienda, el gobierno argentino reconoció la legitimidad de su par republicano, negándose a ceder ante las presiones de los emisarios del bando sublevado para bregar por un cambio en ese punto. ${ }^{72}$ Fue recién hacia finales de febrero de 1939 cuando Roberto Ortiz, presidente de la Argentina desde febrero de 1938, decidió conceder al gobierno de Burgos ese reconocimiento, advirtiendo el control absoluto que las fuerzas franquistas ejercían sobre la mayor parte de España.

Los dirigentes del PCA lograron hacer oír su voz desde las páginas de la prensa burguesa (como fue el caso del periódico Crítica, que por entonces tenía una tirada habitual superior a los 400.000 ejemplares) y en los periódicos de asociaciones interclasistas (como fue la experiencia de La Nueva España). Pero toda vez que los comunistas intentaron, durante los años considerados, dirigirse al público desde sus propios órganos de prensa, debieron padecer la censura y la represión. Así, se había entablado un proceso contra algunos de los miembros y colaboradores de Soviet, la revista teórica del partido, entre ellos Rodolfo Ghioldi, Paulino González Alberdi, Héctor P. Agosti, Miguel Contreras, Orestes Ghioldi, Oscar Creydt, José Peter, Juan Núñez. Incluso el propietario de la imprenta había sido inculpado por actividades ilícitas. Y hasta el mismo órgano del partido, La Internacional, debió ser cancelado a raíz de los fuertes golpes asestados al amparo de la nueva Ley de Represión Anticomunista, que desde entonces fue suplantado por el periódico Hoy. De hecho, según se comenta en La Internacional del 11 de agosto de 1934, había pasado un mes desde el levantamiento del estado de sitio, pero la represión y la censura continuaban recayendo sobre los trabajadores y sobre el PCA, ${ }^{73}$ y no fue hasta diciembre que la Cámara Federal de Apelaciones ordenó la liberación de Contreras, Peter, Núñez y Creydt.

Además de Codovilla acudieron a suelo español procedentes del PCA, aunque en un lapso menor y con menor incidencia política para el PCE

la exhibición del vehículo equipado antes de que partiera el 10 de mayo de 1937 hacia España, pero el gobierno nacional prohibió terminantemente que fuera exhibida en público. «Prohibieron la exhibición de la ambulancia», La Nueva España, 6/5/1937, p. 1.

72 Silvina Montenegro, op. cit., p. 93.

73 «iLibertad de los presos sociales!», La Internacional, 11/8/1934, año XVIII, N. ${ }^{\circ} 3435$, pp.1-2. 
- mas no así para la sección argentina de la IC - , muchos de sus principales cuadros partidarios, juveniles y sindicales: España Juan José Real, Miguel Burgas, Luis V. Sommi, Miguel Contreras, Francisco Muñoz Diez, Benigno Mochkofsky, Bernardo Edelman, Fanny Jacovsky, Jesús Manzanelli, José Manzanelli, Angel Ortelli, José Acosta, Raquel Levenson. Todos ellos antepusieron la defensa de la causa republicana en España, postergando sus tareas directamente comprometidas con el desarrollo del comunismo en la Argentina.

En momentos en que la Argentina pasaba por un proceso de profunda reacción antidemocrática y en el cual los comunistas se veían obligados a desarrollar formas eficientes de actividad clandestina, resultaba ser que la reconversión de la línea política del partido desde la táctica de «clase contra clase» a la de «frente popular» tenía que ser llevada a cabo por los pocos dirigentes de peso que habían permanecido en el país junto con los militantes de segunda línea, carentes de una formación teórica y de una experiencia de lucha adecuadas. Y ello en el mismo instante en que en la experiencia novedosa de la heterogénea CGT se llevaba a cabo una situación de «cooperación competitiva» con los socialistas y los sindicalistas dirigida a ganar la conducción de las masas trabajadoras. De todas formas la campaña para la conversión del PCA en un partido de masas, sin llegar a concretarse, le permitió salir del reducto al que lo había aislado la orientación política de «clase contra clase».

Puede pensarse que las altas autoridades de la IC hubiesen interpretado que los mandos argentinos se encontraban ociosos - además de en peligro constante - a causa de las circunstancias políticas imperantes en el país y hayan entendido que se encontraban en condiciones de realizar un mayor aporte al movimiento comunista internacional en aquellas regiones en que los partidos comunistas contaban con cierto margen de acción para operar sobre las coyunturas políticas nacionales. Urge recordar que tras el derrocamiento de Yrigoyen, el agente soviético Guralsky (nombre real Abraham Jeifetz), encargado de dirigir la escuela de cuadros que funcionaba en el PCA, se trasladó junto a su alumnado a Montevideo, donde también se asentó el Secretariado Sudamericano de la IC. ${ }^{74}$ Pero lo cierto

${ }^{74}$ Cf. Horacio Tarcus, «Los «rojos» para Yrigoyen y Perón», Clarín, 31/8/1997 [tomado de http://edant.clarin.com/diario/1997/09/02/suplementos/i-00301h.htm. Ultimo acceso: 22/6/2011]; Isidoro Gilbert, El oro de Moscú. Historia secreta de la diplomacia, el comercio y la inteligencia soviética en la Argentina, Sudamericana, Buenos Aires, 2007, p. 52 . 
es que el momento histórico argentino se manifestaba altamente contrario a las conveniencias de dejar acéfalo a un partido con las características verticalistas propias del PCA de aquellos tiempos.

Para la IC las tareas más inmediatas del PCA estaban en función de las necesidades soviéticas en otras partes del globo. La Sección Argentina de la Tercera Internacional, que durante tantos años se había ocupado de consolidar una relación quasi-simbiótica con Moscú, acudió inmediatamente a su llamado, aun cuando ello suponía abandonar el crecimiento del comunismo en su propia base de operaciones. Y todo esto sucedía en el exacto momento en que el partido argentino comenzaba a plantearse la necesidad de abandonar el ostracismo político al que lo condenaban la represión estatal y su propia posición sectaria para pasar a interactuar con las fuerzas democráticas en la conformación de un frente popular antifascista. No obstante, los comunistas argentinos se las arreglaron para presentar en Moscú una imagen favorable del trabajo realizado a nivel local. En 1933 el PCA registraba más de 4000 miembros. Aunque se pudiera considerar que estas cifras eran moderadas, significaba un incremento notable en relación a los 2000 afiliados con los que afirmaban haber contado un año antes. En la ciudad de Buenos Aires operaban 32 células. $^{75}$

El sacrificio de algunos intereses locales fundamentales del PCA en función de los requerimientos especiales acordados en los centros de decisión del comunismo internacional iba más allá de las afectaciones que podía encontrar la dirección del partido. El historiador Daniel Kersffeld contribuye a explorar el complejo de relaciones entre la IC y el comunismo argentino al señalar la negativa por parte de los judíos comunistas miembros del PCA a denunciar los vejámenes a que eran condenados los miembros de su comunidad en Alemania desde mediados de la década de 1930. La Unión Soviética aparecía para las poblaciones que profesaban la religión judía como el único territorio seguro frente al crecimiento del nazismo en Alemania y su expansión internacional. ${ }^{76} \mathrm{La}$ defensa de la Segunda República española primero, y el pacto acordado entre Ribbentrop y Molotov después, determinaron el orden de prioridades dispuesto entonces por la Comintern. Los judeocomunistas argentinos respondieron, respectivamente, creando la Comisión Israelita de Ayuda a España y adhi-

75 Acta de las sesiones del Secretariado Latinoamericano, 1933, p. 27, Archivo IC, BCNA, r. 3, s. 16 [En ruso].

76 Daniel Kersffeld, Rusos y rojos. Judíos comunistas en tiempos de la Comintern, Capital Intelectual, Buenos Aires, 2012, p. 48. 
riendo a la interpretación de que en la Segunda Guerra Mundial se estaba consumando una guerra interimperialista en la que era imperativo mantener la neutralidad. ${ }^{77}$ El comportamiento de los judíos comunistas de la Argentina constituye un notable ejemplo del tipo de lealtades que podían llegar a generar las políticas de la IC a partir de la promulgación del programa de tareas inmediatas del momento.

\section{Consideraciones finales}

La sublevación franquista tuvo repercusiones inmediatas en las distintas secciones nacionales que componían la IC. En el PCA su impacto fue especialmente significativo. La Guerra Civil española generó condiciones especiales para la penetración del comunismo en la sociedad argentina, y el PCA no desaprovechó la oportunidad que se le presentaba. Para ello debió romper abruptamente con la prédica que hasta entonces había profesado, conduciendo su reconversión de partido en vías de bolchevización en un partido con intenciones de masificarse mediante una fuerte inserción en los núcleos democráticos centrales de la sociedad y sin que ello significara un abandono a lograr posiciones de poder cada vez mayor dentro del movimiento obrero. En este sentido, y como parte de un creciente caudal de trabajos «que se dedican a estudiar la contienda española e investigan aspectos de la participación que en ella tuvieron los diversos Estados extranjeros» ${ }^{78}$, nuestro interés estuvo puesto en señalar el aporte del PCA en la lucha antifascista por la defensa de la causa republicana en tiempos en que había sido proscripto, sus actividades se hallaban ilegalizadas y sus miembros eran víctimas de la represión estatal.

La colaboración con el comunismo español supuso para los comunistas argentinos el alejamiento de sus mayores organizadores. Todo ello tuvo lugar en una coyuntura política extraordinaria que se caracterizó, en gran parte, por una feroz represión al comunismo y en la cual se privó a un partido constituido sobre las bases del verticalismo de su más preciado

77 Idem, pp. 139-140. El sector de la comunidad judía que integraba el PCA se volcó con especial entusiasmo a la creación de la Comisión Israelita de Ayuda a España, el cual desarrolló una importante red de organización y propaganda a través de la publicación de un periódico en idish y la apertura de quince filiales en el interior del país.

78 Yuri Rybalkin, Stalin y España. La ayuda militar soviética a la República, Madrid, Marcial Pons, 2007, p. 21. 
elemento: la dirección. El descabezamiento parcial del PCA y de la Federación Juvenil Comunista, a partir del traslado de muchos de sus más eminentes cuadros hacia «zonas calientes» - urge recordar los trabajos de organización partidaria emprendidos por Rodolfo Ghioldi en España primero $^{79}$ y a partir de fines de 1934 en la insurrección de la Alianza Nacional Libertadora liderada por Carlos Prestes en Brasil (finalmente perpetrada en el mes de noviembre de 1935) - demuestra el valor instrumental que se adjudicaban a sí mismos los líderes del PCA frente a las necesidades trazadas por la IC. A la hora de resolver los tres grandes conflictos internos que debió atravesar a lo largo de la década de 1920, la dirección argentina otorgó a la IC un lugar de intervención en sus asuntos locales que excedía el compromiso que Moscú se hallaba dispuesta a asumir. Esta praxis política conllevó a un alineamiento dogmático con la IC. De igual modo, para disgusto de Palmiro Togliatti, cuando Codovilla llegó a España pretendió situar la dirección del PCE bajo el mando del Comité Ejecutivo de la IC, reproduciendo la misma lógica aplicada en el PCA desde 1928.

La falta de estudios acerca del compromiso adoptado por el PCA con la causa republicana dio lugar a afirmaciones como aquella formulada por el historiador Luis Alberto Romero acerca de que fue el PSA el partido político que «constituyó el primer y más firme apoyo a la República». Para sostener su postura, Romero señala que los vínculos entre el Partido Socialista Argentino «con las asociaciones españolas, especialmente con las gallegas, eran estrechos. Sus militantes fueron siempre activistas del sindicalismo y del movimiento cultural popular reformista. Los centros socialistas, al igual que los sindicatos dirigidos por ellos, se constituyeron en la base de los grupos solidarios. La Unión Ferroviaria, por ejemplo, a través de sus seccionales, facilitó la extensión del movimiento por todo el país» ${ }^{80}$. No obstante, según ha quedado demostrado, este planteo debe ser matizado a la luz de los hechos del pasado, pues el compromiso activista desplegado por el PCA parece haber superado los efectos de aquel cúmulo de acciones socialistas cuya incidencia, si bien importante, resultaban más

${ }^{79}$ Cuando Codovilla es encarcelado en España, Ghioldi es designado por el CE de la IC en su XII Pleno, por pedido expreso de Manuilski, para supervisar el trabajo del órgano del PCE, Mundo Obrero, cargo que desempeña hasta su partida a Moscú en 1934. Cf. Horacio Tarcus, Diccionario biográfico de la izquierda argentina, Buenos Aires, Emecé, 2007 , p. 253.

${ }^{80}$ Luis Alberto Romero, op. cit., p. 24. 
limitada para el desarrollo de los acontecimientos tanto nacionales como internacionales. Sin lugar a dudas el PCA fue una fuerza más dentro del conjunto de nucleamientos políticos, sociales y gremiales que pusieron la lucha antifascista en el frente de batalla español entre sus programas de acción más inmediatos. Para el PCA la causa republicana tuvo un doble significado: por un lado tuvo una participación destacada en la organización de la ayuda al gobierno constitucional de España, mientras que por el otro fue el partido que, corriendo con los mayores riesgos de sanción por parte del Estado argentino, más transformaciones internas registró a partir de su activismo. 